\title{
Benign Fibrous Histiocytomas of the Oral Mucosa: Report on Three Cases and Review of the Literature
}

\author{
Laure-Anne Prisse $^{a}$ Primali Rukmal Jayasooriya ${ }^{b}$ \\ Balapuwaduge Ranjit Rigorbert Nihal Mendis ${ }^{a}$ Tommaso Lombardi ${ }^{a}$ \\ a Unit of Oral Medicine and Oral and Maxillofacial Pathology, Division of Oral and \\ Maxillofacial Surgery, Department of Surgery, University of Geneva and University Hospitals \\ of Geneva, Geneva, Switzerland; b Department of Oral Pathology, Faculty of Dental Sciences, \\ University of Peradeniya, Peradeniya, Sri Lanka
}

\section{Key Words}

Benign fibrous histiocytoma $\cdot$ Literature review $\cdot$ Management

\begin{abstract}
Benign fibrous histiocytomas (BFH) of the skin are common lesions, although they only rarely involve the oral mucosa. This article presents 3 additional cases of $\mathrm{BFH}$ of the oral mucosa, with a review of previously published cases. Although a malignant variant of $\mathrm{BFH}$ also exists, the present review focuses only on benign lesions. The clinical presentation, diagnosis, histopathological and immunohistochemical features of BFH are discussed. According to the present analysis, the majority of oral mucosal BFH have occurred in middle-aged and elderly patients, with a slight female predilection. Within the oral cavity, BHF may occur at any mucosal site, including the lips, tongue, buccal mucosa, mandibular and maxillary gingiva as well as the palate. Histopathology is essential to diagnose the lesion, while immunohistochemical investigations may be utilized to exclude the histopathological differential diagnoses such as juvenile xanthogranulomas and nevi. This review also revealed total excision as the treatment of choice for $\mathrm{BFH}$, with a very good prognosis and an extremely low rate of relapse.
\end{abstract}

(C) 2015 S. Karger AG, Basel

\section{Introduction}

Benign fibrous histiocytoma (BHF) designates a group of quasi-neoplastic lesions that show both fibroblastic and histiocytic differentiation. Whether the lesions originate from histiocytic or fibroblastic tissues has not been clearly determined yet. Some experts hypoth- 
esize that the cells originate from the tissue histiocytes and then assume fibroblastic properties [1], while others argue that immunohistochemical evidence of factor XIIIa positivity favors a dermal dendrocytic cell origin [2]. In consequence of the controversies of origin, over the years, BFH have been designated by several different names, such as sclerosing hemangioma, histiocytoma cutis, fibroxanthoma and nodular subepidermal fibrosis [1].

Although BFH may occur anywhere in the body, including in visceral organs, skeletal system or sinuses, the majority arise on the skin of the extremities [2]. When BHF occur in the dermis, the lesions are designated as dermatofibromas. Furthermore, BFH are also classified as superficial and deep lesions, depending on the location [2].

Only rarely lesions may involve the oral mucosa or jaw bones [3-31]. In the oral mucosa, BFH show a predilection to the buccal mucosa and vestibule [1, 4-31]. Compared to oral mucosal lesions, intraosseous lesions that involve the jaw bones are extremely uncommon, with 7 cases of mandibular and 2 maxillary BFH reported to date [3].

The purpose of this article is to report 3 additional cases of BHF of the oral mucosa and to review the current literature on this topic.

\section{Case Reports}

\section{Case 1}

A 48-year-old female, in good general health, presented to our consultation 7 months after the onset of a lesion of the left lower lip. The lesion had appeared after the patient bit her lip and evolved by fluctuating in size, alternately growing and diminishing. It was painful, which motivated the patient's consultation. The mucosal appearance was banal (no picture available). It was completely excised under local anesthesia.

The macroscopic examination revealed a greyish mucosal sample measuring $0.8 \times 0.8 \times$ $0.3 \mathrm{~cm}$ with central ulceration. The histopathological examination showed inflammatory ulceration of the labial mucosa with the deep aspect of the lesion located in a thickened submucosa. The ulcerated area was covered by a coating of fibrin, debris and leukocytes (fig. 1). The principal cell population consisted of an irregularly arranged compact proliferation of histiocyte-like cells with a clear cytoplasm and a nucleus containing a prominent nucleolus (fig. 2). The submucosa contained numerous small blood vessels collapsed by the turgescence of the endothelial cells. Between these vessels, there was a dense chronic and polymorphic inflammatory infiltrate also composed of few polymorphonuclear cells. The epithelium was hyperplasic. There were no sign of malignancy within the limits of the sample. Immunohistochemical stains showed positivity for CD68 (fig. 3) and vimentin, negativity for MNF116, S-100 protein, CD34, smooth-muscle actin (SMA) and desmin. The diagnosis rendered was BHF of traumatic origin.

\section{Case 2}

A 75-year-old male presented with a $0.5 \times 0.5 \mathrm{~cm}$ round lump of a hard consistency on the posterior palate. The lesion was excised under local anesthesia, and the histopathological examination revealed a mucosal nodule covered by orthokeratinized stratified squamous epithelium. A circumscribed but unencapsulated wedge-shaped lesion was evident in the corium, composed of spindle cells arranged in a storiform pattern in several foci (fig. 4). Histiocytes containing clear cytoplasms and central nuclei were also noted. Elsewhere, the stroma was densely fibrous and was composed of hyalinized eosinophilic collagen fiber bundles. Marked basal cell hyperpigmentation was also evident. This fact led us to exclude an intramucosal nevus using S-100 immunostain. Furthermore, SMA negativity was useful to exclude leiomyoma. Thus, the final diagnosis rendered was BFH. 


\section{Dermato pathology}

Fig. 1. The lesion with central ulceration. $\times 4$.

Fig. 2. Irregular disposition of histiocyte-like cells. $\times 40$.

Fig. 3. Strong immunohistochemical positivity for CD68. $\times 40$.

\begin{tabular}{l|l}
\hline Dermatopathology 2015;2:52-60 \\
\hline DOI: 10.1159/000381618 & $\begin{array}{l}\text { @ 2015 S. Karger AG, Basel } \\
\text { www.karger.com/dpa }\end{array}$ \\
\hline
\end{tabular}

Prisse et al:: Benign Fibrous Histiocytomas of the Oral Mucosa: Report on Three Cases and Review of the Literature
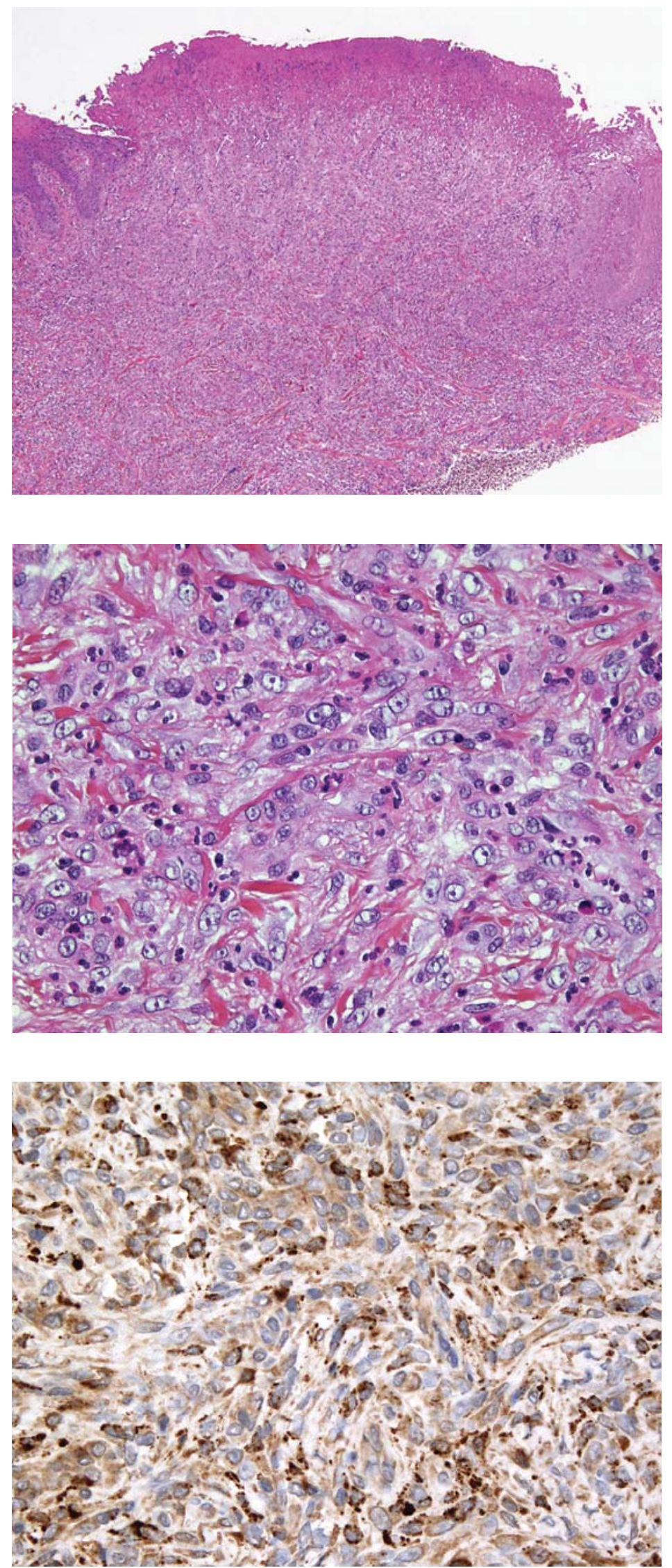


\section{Dermato pathology}

Fig. 4. Spindle cells arranged in a storiform pattern. $\times 10$.

Fig. 5. Rich cellularity of the tumor mass. $\times 20$.

Fig. 6. Vimentin-positive staining of the lesion cells. $\times 20$.

\begin{tabular}{l|l}
\hline Dermatopathology 2015;2:52-60 \\
\hline DOI: 10.1159/000381618 & $\begin{array}{l}\text { @ 2015 S. Karger AG, Basel } \\
\text { www.karger.com/dpa }\end{array}$ \\
\hline
\end{tabular}

Prisse et al.: Benign Fibrous Histiocytomas of the Oral Mucosa: Report on Three Cases and Review of the Literature
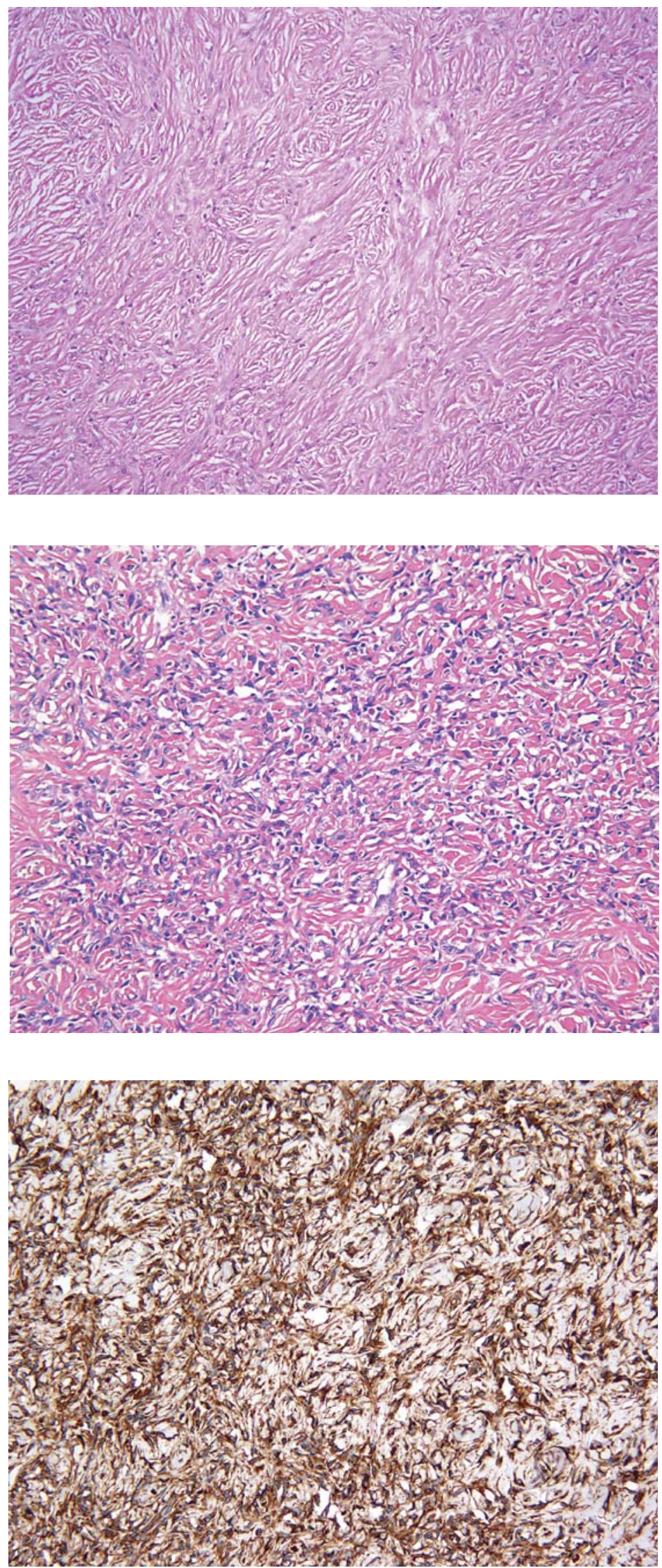
Case 3

An 81-year-old male presented with a firm pedunculated $3 \times 3 \mathrm{~cm}$ lump on the hard and soft palate junction of 6 months duration. The overlying mucosa was pink in color and without ulceration. No significant radiological changes were evident. Histopathology revealed a mucosal nodule covered by atrophic orthokeratinized stratified squamous epithelium. A few foci of the tumor were richly cellular (fig. 5), composed of spindle cells arranged in a storiform pattern. Some cells showed pleomorphic nuclei with smudged chromatin and minimal cytoplasm. Elsewhere, densely sclerotic stroma composed of collagen fiber bundles was noted. Immunohistochemical investigations with SMA, S-100 and vimentin revealed tumor-cell positivity to vimentin (fig. 6) and sparsely for CD68. Thus, the final diagnosis was BFH. The lesion did not recur during the 6-year follow-up period.

Table 1 shows the clinicopathological presentations of 47 cases of oral BFH published until 2014.

\section{Discussion}

Based on the literature review and the present cases, $\mathrm{BFH}$ of the oral mucosa were found to clinically present as slowly growing, painless masses [5]. Although these lesions do not produce any repercussion on the patients' general health, they may have local consequences, for example interfere with mastication and compress or displace anatomical structures. Rarely, multiple BFH may occur due to immunosuppression [2], but none of the oral BHF reviewed had presented as multiple lesions [4-31]. The overlying mucosa remains most often intact but can show periods of ulceration [4] due to traumatism, in which case lesions may become painful. Majority of the lesions are freely mobile and have no associated lymphadenopathy.

Oral mucosal BFH most often occur in middle-aged to older adults [4-31] compared to the cutaneous counterpart, which occurs predominantly in young adults [2]. Oral mucosal $\mathrm{BFH}$ are slightly more often encountered in female patients, similar to dermatofibromas. Macroscopically, BFH are generally round to oval-shaped, whitish to yellowish and firm. The lesions are well demarcated from surrounding tissues but not properly encapsulated [4-31].

Histologically, there is a dual cell population of fibroblasts and histiocytes. Occasional multinucleated giant cells, lipid-containing xanthoma cells and lymphocytes can be found [1, 2]. The fibroblasts are spindle-shaped and arranged in a storiform pattern or short fascicles [2]. The cells do not show any sign of malignancy, and mitoses are extremely rare. The stroma is densely fibrous and may show areas of myxoid change or focal hyalinization [1]. Variants of BFH include cellular fibrous histiocytomas, epithelioid fibrous histiocytomas, aneurysmal fibrous histiocytomas as well as clear cell, lipidized, palisading, myxoid and granular cell types [2]. In addition, Han et al. [32] classify dermatofibromas as fibrocollagenous, histiocytic, cellular, aneurysmal, angiomatous, sclerotic, monster, palisading and keloidal dermatofibromas. According to their classification, the BFH described in the present report can be classified as fibrocollagenous BFH (case 1) and sclerotic BFH (cases 2 and 3).

According to the literature, BFH show different patterns of positivity with immunohistochemical stains. Most lesions show a strong tendency for positivity with vimentin and CD68. Positivity for SMA and factor XIIIa is often reported [1]. Further, the immunohistochemical features may vary over time, with early lesions of dermatofibromas showing reactivity for CD68 and factor XIIIa, which may diminish progressively. CD56 and neuron-specific enolase are variably expressed, and S-100 protein is only exceptionally expressed [19]. Lysozyme can also be positive. In our cases, the positivity for vimentin and CD68 and the negativity for MNF116 (keratin), S-100 protein (neurological marker), CD34 (vascular marker), SMA and desmin confirmed the diagnosis of BFH. 


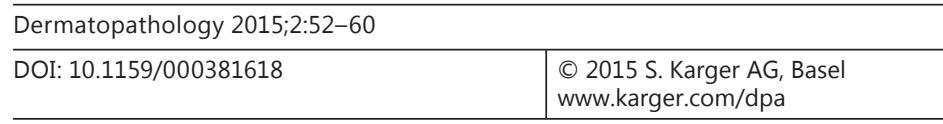

Prisse et al.: Benign Fibrous Histiocytomas of the Oral Mucosa: Report on Three Cases and Review of the Literature

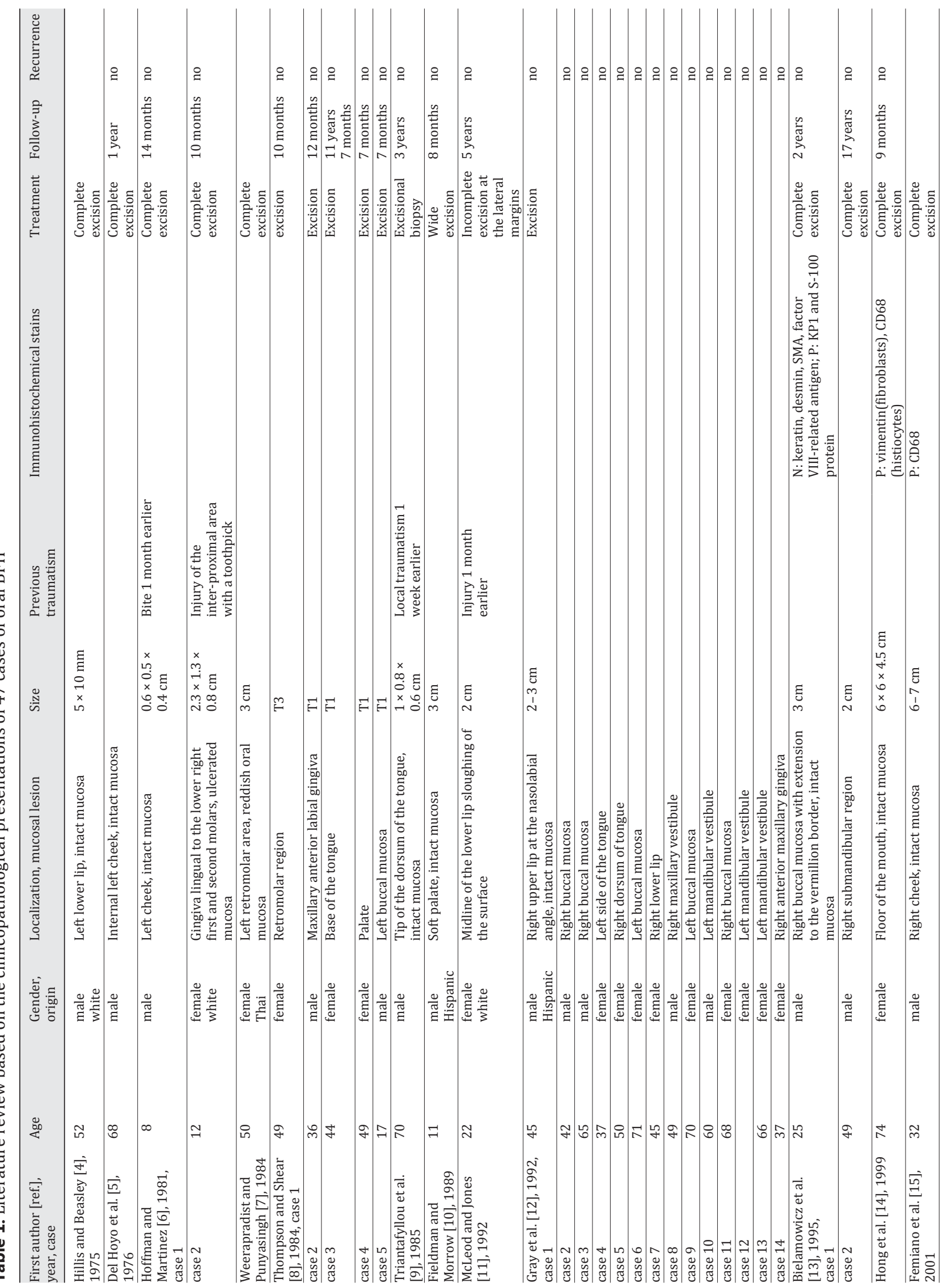




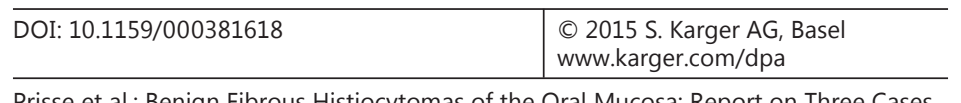

Prisse et al.: Benign Fibrous Histiocytomas of the Oral Mucosa: Report on Three Cases and Review of the Literature

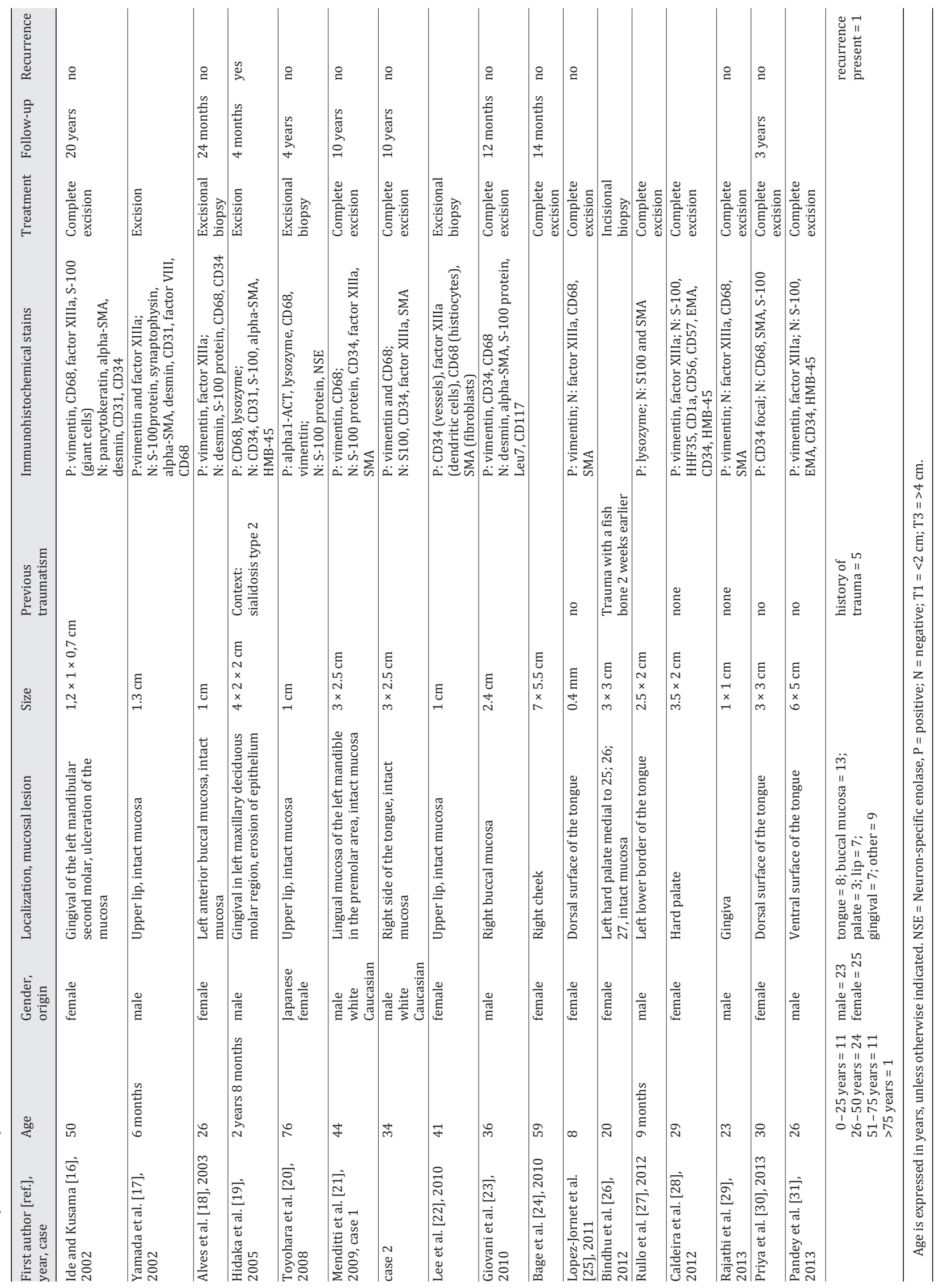


Although factor XIIIa is a marker that has been considered to confirm the diagnosis of $\mathrm{BFH}$, it may also show positivity in other mesenchymal tumors [2]. At present, there are no specific immunohistochemical markers to diagnose fibrohistiocytic lesions, including BFH. Thus, BFH are diagnosed by the exclusion of entities with similar features such as juvenile xanthogranuloma (S-100, CD1a positive), leiomyomas (SMA positive), dermatofibrosarcoma protuberance (DFSP; CD34 positive) as well as by the absence of positive staining with immunohistochemical markers other than vimentin, factor XIIIa and CD68 [23]. However, it is also important to remember that cellular BFH may show focal reactivity to CD34, in which case it may be relatively difficult to differentiate it from DFSP [2]. However, with regard to oral lesions, this problem may not arise as DFSP is a primarily cutaneous lesion.

Even though it is not possible to highlight such an event in every case reported, BFH can sometimes be related to a previous local injury or infection. There remains a long controversy about the origin of $\mathrm{BFH}$, and it is not clear yet whether $\mathrm{BFH}$ arise as true neoplasms on sound mucosa or as a reaction to a previous traumatism [22]. Only in 5 cases of our review (2 cases in [6], [11, 13, 24]) and in case 1 of the present series, which appeared after a bite, such a traumatism is clearly mentioned.

Out of the BFH of the oral mucosa, only a small number involves the lips: 8/51 cases (taking our patient into account); 3 of the lesions occurred on the lower lip [4, 11, 12], 4 on the upper lip $[12,17,20,22]$ and 1 additional case involved the buccal mucosa with extension to the vermillon border of the lower lip [13].

Our case 1 presented with an ulceration of the overlying mucosa, which is less common than an intact mucosa. Out of the 51 cases of our review, 19 had a normal overlying mucosa, 26 were not specified and only 6 showed mucosal alterations, varying from moderate inflammation [23] or erythematous mucosa [7] to proper ulceration [6, 1, 19].

Fibrous histiocytoma has a malignant form, which is more often encountered in the literature. An intermediately aggressive variant (angiomatoid variant) has also been recognized since 1995 [27] and is described as having a local aggressiveness and a low rate of metastasis $[27,12]$.

In accordance to the other cases reported in the literature since 1975, the lesions had no consequence on the good general health of our patients and showed a slow growing pattern. Treatment of BFH consists of complete excision and has an excellent prognosis as recurrence is exceptional. Out of the 43 selected patients, only 1 case of recurrence is described in a twoyear-old infant [19]. Forty-three cases were disease free at follow-up, which was between 7 months and 20 years, and for 7 cases, follow-up was not specified.

\section{Conclusion}

As BFH has a banal appearance, diagnosis or distinction from other types of nodules is impossible on a clinical basis. Histological examination is mandatory as it is the only way to confirm the benignity of the lesion. The cases we reported were relatively typical, and the clinical course corresponded to that of the other cases found in the literature, confirming the low risk of recurrence after complete excision.

\section{Disclosure Statement}

The authors declare no conflicts of interest. 
Prisse et al.: Benign Fibrous Histiocytomas of the Oral Mucosa: Report on Three Cases and Review of the Literature

\section{References}

1 Neville BW, Damm DD, Allen CM, Bouquot JE (eds): Oral and Maxillofacial Pathology, ed 2. Philadelphia, WB Saunders, 2001, pp 368-369.

2 Weiss S, Goldblum J (eds): Enzinger and Weiss's Soft Tissue Tumors, ed 5. St Louis, Mobsy, 2008, pp 331-348.

-3 Saluja H, Kasat VO, Rudagi BM, Dehane V, Kalburge JV, Nikam A: Benign fibrous histiocytoma of the maxilla: a case report and review of the literature. Indian J Dent Res 2014;25:115-118.

4 Hillis RE, Beasley JD: Fibrous histiocytoma of the lip: report of a case. J Oral Med 1975;30:81-83.

5 del Hoyo JA, Contreras F, Gonzales FD: Fibro-histiocytome de la cavité buccale. Rev Stomatol Chir Maxillofac 1976;77:481-483.

6 Hoffman S, Martinez MG: Fibrous histiocytoma of the oral mucosa. 1981;52:277-283.

7 Weerapradist W, Punyasingh J: Fibrous histiocytoma: report of a case of the oral mucosa. J Dent Assoc Thai 1984;34:263-269.

8 Thompson SH, Shear M: Fibrous histiocytomas of the oral and maxillofacial regions. J Oral Pathol 1984;13: 282-294

-9 Triantafyllou AG, Sklavounou AD, Laskaris GG: Benign fibrous histiocytoma of the oral mucosa. J Oral Med 1985;40:36-38.

10 Fieldman RJ, Morrow TA: Fibrous histiocytoma of the soft palate. Int J Pediat Otorhinolaryngol 1989;18:171179.

11 McLeod SPR, Jones JL: Fibrous histiocytoma of the lip secondary to trauma: report of a case. J Oral Maxillofac Surg 1992;50:1091-1093.

$\$ 12$ Gray PB, Miller AS, Loftus MJ: Benign fibrous histiocytoma of the oral/perioral regions: report of a case and review of 17 additional cases. J Oral Maxillofac Surg 1992;50:1239-1242.

-13 Bielamowicz S, Dauer MS, Chang B, Zimmerman MC: Non-cutaneous benign fibrous histiocytoma of the head and neck. J Otolaryngol Head Neck Surg 1995;133:140-146.

14 Hong KH, Kim YK, Park JK: Benign fibrous histiocytoma of the floor of the mouth. J Otolaryngol Head Neck Surg 1999;121:330-333.

15 Femiano F, Scully C, Laino G, Battista G: Benign fibrous histocytoma (BFH) of the cheek: CD68-KP1 positivity. Oral Oncol 2001;37:673-675.

16 Ide F, Kusama K: Benign fibrous histiocytoma: an additional case richly endowed with factor XIIIa cells. Oral Oncol 2002;38:321-322.

17 Yamada H, Ishii H, Kondoh T, Seto K: A case of benign fibrous histiocytoma of the upper lip in a 6-month-old infant. J Oral Maxillofac Surg 2002;60:451-454.

18 Alves, FA, Vargas PA, Coelho Sicueira SA, Coletta RD, De Alemida OP: Benign fibrous histiocytoma of the buccal mucosa: case report with immunohistochemical features. J Oral Maxillofac Surg 2003;60:451-454.

19 Hidaka M, Yamashita A, Sakamoto K, Mukaisho K, Hattori T, Yamamoto G: Benign fibrous histiocytoma occured in the alveolar mucosa accompanying with sialidosis type 2 in a Japanese infant. Oral Oncol 2005;41:253-258.

20 Toyohara Y, Hashitani S, Sakurai K, Takaoka K, Urade M: Benign fibrous histiocytoma of the upper lip: a case report. Oral Science Internat 2008;5:65-68.

21 Menditti D, Laino L, Mezzogiorno A, Sava S, Bianchi A, Caruso G, Di Maio L, Baldi A: Oral benign fibrous histiocytoma: two case reports. Cases J 2009;2:9343.

22 Lee HI, Lee JW, Han TY, Li K, Hong CK, Seo SJ, Song K: A case of dermatofibroma of the upper lip. Ann Dermatol 2010;22:333-336.

23 Giovani P, Patrikidou A, Ntomouchtsis A, Meditskou S, Thuau H, Vahtsevanos K: Benign fibrous histiocytoma of the buccal mucosa: case report and literature review. Case Rep Med 2010;2010:306148.

24 Bage AM, Bylappa K, Kumar MV: A rare case of fibrous histiocytoma of subepidermal soft tissue of cheek (buccal mucosa). Internet J Otorhinolaryngol 2010;13:11.

25 Lopez-Jornet P, Camacho-Alonso F, Gomez-Garcia FJ: Oral lesion of the dorsum of the tongue. J Can Dent Assoc 2011;77:b117.

26 Bindhu PR, Padmakumar SK, Priya T, Jacob J: A rare case of benign fibrous histiocytoma in the submucosal soft tissue of the hard palate: a case report and review of the literature. Oral Maxillofac Pathol J 2012;3:215-217.

27 Rullo R, Ferraraccio F, Serpico R, Addabbo F, Mazzarella N, Maria Festa V: Oral fibrous histiocytoma and its angiomatoid variant. J Craniomaxillofac Surg 2012;40:435-438.

-28 Caldeira PC, Ribeiro DC, Almeida OP, Mesquita RA, Do Carom MAV: Tumour of the hard palate. Oral Surg Oral Med Oral Pathol Oral Radiol 2012;113:722-727.

-29 Rajathi P, Jacob M, Priyadarshani I, Sekar B: Benign fibrous histiocytoma of the gingiva. J Pharm Bioallied Sci 2013;5(suppl 2):S166-S168.

30 Priya NS, Rao K, Umadevi HS, Smith T: Benign fibrous histiocytoma of the tongue. Indian J Dent Res 2013;24: 635-638.

31 Pandey NK, Sharma SK, Banerjee S: A rare case of fibrous histiocytoma of the tongue. Indian J Surg 2013; 75(suppl 1):1-5.

-32 Han TY, Chang HS, Lee JHK, Lee W-M, Son S-J: A clinical and histopathological study of 122 cases of dermatofibroma. Ann Dermatol 2011;23:185-192. 